

\section{Música e biografia no documentário brasileiro: uma análise semiopragmática de $A$ música segundo Tom Jobim ${ }^{1}$}

Music and biography in Brazilian documentary: a semiopragmatic analysis of A música segundo Tom Jobim

\section{Resumo}

O presente artigo pretende discutir os limites entre o biográfico e o musical no contexto da produção documental brasileira contemporânea. Para tanto, apresenta uma análise semiopragmática de $A$ música segundo Tom Jobim (2011), documentário que se caracteriza pelo protagonismo da matéria musical e que aponta para a possibilidade de expansão dos limites do documentário biográfico musical para além de sua fórmula mais corrente, normalmente centrada no recurso de depoimentos.

\section{Palavras-chave}

Documentário; música; biografia; semiopragmática.

\section{Abstract}

The present article intends to discuss the boundaries between the biographical and the musical in the context of contemporary Brazilian documentary production. For that, it presents a semiopragmatic analysis of $A$ música segundo Tom Jobim (2011), a documentary that is characterized by the protagonism of the musical matter and that points to the possibility of expanding the limits of the musical biographical documentary beyond its more current, usually centered formula in the resource of testimonies.

\section{Keywords}

Documentary; music; biography; semiopragmatic. 


\section{Introdução}

Ainda que a categoria do "documentário musical" careça de precisão teórica enquanto um subgênero nos domínios do cinema documental (Lima, 2015), seu reconhecimento pela crítica, assim como pelo público que atualmente frequenta as salas de cinema no Brasil, é inegável. Consideramos aqui, em consonância com Altman (1999), que gêneros e seus subgêneros são categorias instáveis, já que histórica e culturalmente delimitadas. Desse ponto de vista, eles não se constituem exclusivamente por marcas de identidade genérica inscritas no corpo dos próprios filmes, mas sobretudo no circuito multidirecional que se estabelece entre estes e os polos da produção, da crítica e da recepção cinematográficas.

Em levantamento preliminar realizado pelo Laboratório de Análise Fílmica (LAF/Póscom-UFBA) durante pesquisa sobre o cinema musical na América Latina, se observou que, enquanto entre as décadas de 1960 a 1990 foi produzido pouco mais de duas dezenas de documentários que podem ser enquadrados segundo a etiqueta do "musical", desde o início do século XXI já se realizou praticamente uma centena de títulos de natureza semelhante no Brasil.

Mesmo que o objetivo central deste artigo não seja esmiuçar as razões do atual crescimento exponencial na produção de documentários musicais no cenário nacional, deve-se apontar que estas provavelmente se relacionam não a um, mas a múltiplos aspectos. Segundo Ramos (2012, p. 128), "as explicações para o fato têm se resumido a indícios de natureza cultural, como o conhecido apreço dos brasileiros pela música popular", contudo é possível levantar outros fatores que muito provavelmente contribuíram para esse crescimento.
Dentre eles, podemos citar, por exemplo, desde o contexto mais favorável à produção cinematográfica observado a partir dos anos de 1990 no Brasil, com o aumento das possibilidades de captação de recursos e maiores incentivos públicos ao audiovisual, até as dinâmicas existentes entre as indústrias cinematográfica e fonográfica nacionais, as quais podem ser rastreadas desde o fenômeno das chanchadas, passando pelos filmes da Jovem Guarda e pela produção dedicada à geração do rock nos anos de 1980, ou ainda pelo reaquecimento recente da produção de cinebiografias ficcionais de personalidades da música (ou grupos musicais) tais como Cazuza: o tempo não para (Sandra Werneck e Walter Carvalho, 2004), 2 Filhos De Francisco: A história de Zezé Di Camargo \& Luciano (Breno Silveira, 2005), Gonzaga: de pai para filho (Breno Silveira, 2012) e Somos tão jovens (Antônio Fontoura, 2013).

Além desses fatores, cumpre ainda apontar a própria revitalização do gênero documentário no Brasil, observada mais ou menos a partir do mesmo período, como um dentre os elementos que contribuíram para a multiplicação de documentários musicais nas salas de cinema. A esse respeito, é importante observar que, ao menos no campo do documentário, o musical tem se afirmado como uma das vertentes de maior aceitação pelo público e que, portanto, tem representado maior possibilidade de retorno em termos de bilheteria para produtores e cineastas.

Um olhar mais atento a esse universo de aproximadamente 100 documentários musicais brasileiros realizados desde o ano 2000 nos leva a perceber, contudo, que mais da metade dessa produção pode ser compreendida não apenas segundo a chave genérica do "musical", mas também pela do "biográfico". Em ou- tras palavras, a maior parte dessa produção tem sido destinada à construção de cine-retratos de músicos ou grupos musicais específicos. Nesse universo, estão incluídos, por exemplo, os documentários Paulinho da Viola: Meu tempo é hoje (Izabel Jaguaribe, 2004), Nelson Freire (João Moreira Salles, 2003) e Fabricando Tom Zé (Décio Matos Jr., 2004), assim como os mais recentes Titãs, a vida até parece uma festa (Branco Mello e Oscar Rodrigues Alves, 2008), Jards (Erik Rocha, 2012) e Chico: artista brasileiro (Miguel Faria Jr., 2015), isso para citar apenas alguns poucos títulos. No entanto, segundo observa Lima, trata-se de um conjunto de filmes relativamente coeso que, em sua maioria, "estão empenhados em construir uma personalidade coerente e estável para os sujeitos retratados" $(2015$, p. 16). Nesse sentido,

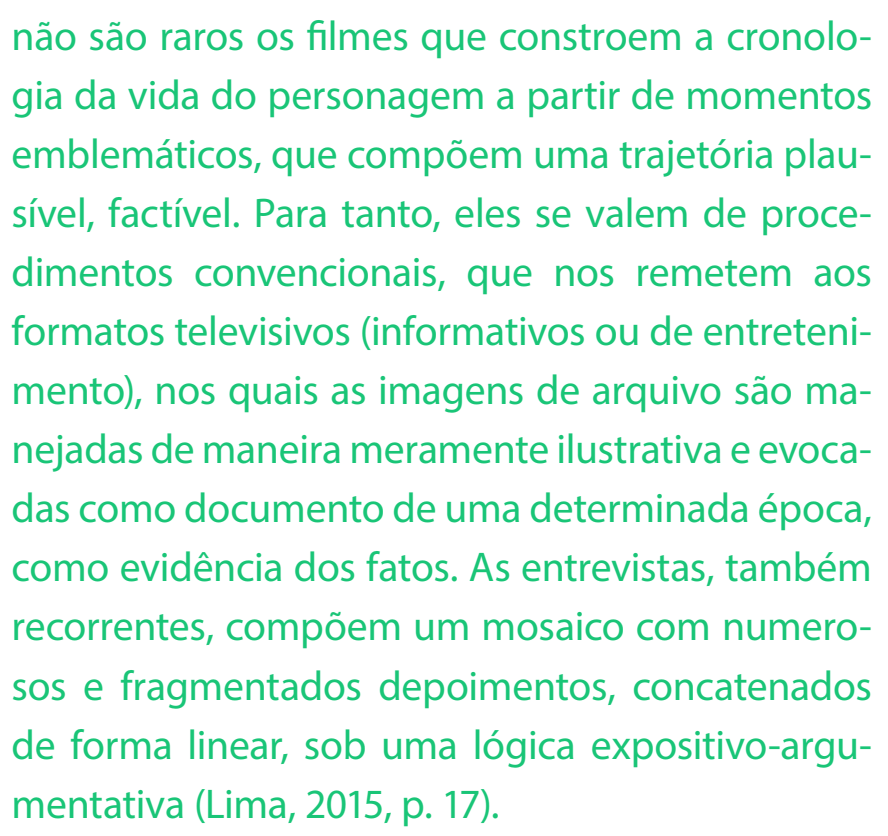
emblemáticos, que compõem uma trajetória plausível, factível. Para tanto, eles se valem de procedimentos convencionais, que nos remetem aos formatos televisivos (informativos ou de entretenimento), nos quais as imagens de arquivo são manejadas de maneira meramente ilustrativa e evocadas como documento de uma determinada época, como evidência dos fatos. As entrevistas, também recorrentes, compõem um mosaico com numerosos e fragmentados depoimentos, concatenados de forma linear, sob uma lógica expositivo-argumentativa (Lima, 2015, p. 17)

Outros autores ainda, como Carvalho (2012; 2015) e Maia (2012), igualmente alinhados com o campo de 
estudos do som no cinema, têm chamado a atenção de seus leitores para o paradoxo de que, na maior parte dessa produção, a música tem sido relegada a um plano acessório em detrimento da voz, se restringindo, quase sempre, a um nível meramente temático. Reivindicam, a partir dessa constatação, que ela possa ocupar um papel de fato estrutural na materialidade fílmica dos documentários musicais, para com isso adquirir uma centralidade que, segundo o ponto de vista defendido por estes autores, deveria caracterizar esse subgênero.

Já para Tavares (2013), autora que tem no aspecto biográfico o foco de sua abordagem, a predominância das biografias musicais no cinema documentário aponta para o fato de que "o investimento neste subgênero do documentário tem sido tão fecundo que são possíveis novas subdivisões como, por exemplo, pensarmos em uma classificação exclusiva para o documentário biográfico musical, um dos veios mais acionados do grupo" (Tavares, 2013, p. 112).

Frente a esse panorama, no qual se evidencia um cenário onde diferentes categorias genéricas se encontram ao mesmo tempo intrincadas e em disputa nos discursos que se debruçam sobre o tema, o presente texto se coloca como uma tentativa de contribuir para a discussão sobre as especificidades atuais do documentário musical no Brasil. Para tanto, opta não apenas por abordar sua faceta mais evidente - a biográfica como por construir sua argumentação a partir da análise da materialidade fílmica de um documentário que se vê inserido nesse cenário, mas que aparentemente se distancia das características mais comumente atribuídas ao documentário musical de caráter biográfico que vem sendo realizado no país.
De acordo com análise de Carvalho (2015), A música segundo Tom Jobim, realizado em 2011 por Nelson Pereira dos Santos e Dora Jobim, nos apresenta "uma biografia que não é didática, informativa e calcada na palavra falada, e sim focada na palavra cantada, na música cantada de Tom Jobim". Mais do que isso, segundo a autora, é um filme que instaura "uma esperança danada de ir ao cinema para ver um documentário sobre temas e personagens da história da música, em particular da MPB, e ser surpreendido por uma nova relação entre imagem e som, música e documentário" (CarvaIho, 2015, p. 129). Nesse sentido, se trataria de um dos raros momentos em que a música, enquanto matéria do audiovisual, alcançou protagonismo no panorama do documentário biográfico musical brasileiro.

É, então, a partir da análise de como se relacionam os aspectos biográficos e musicais durante a fruição do documentário A música segundo Tom Jobim que tentaremos construir uma linha de raciocínio a respeito das articulações genéricas no cenário do documentário musical. Para acionar a análise pretendida, privilegiaremos a utilização da abordagem semiopragmática que foi desenvolvida por Odin (2000), exatamente por esta se ver centrada na identificação dos diferentes posicionamentos de leitura que podem ser acionados pelos espectadores no momento da fruição fílmica. Assim, antes de iniciarmos a análise propriamente dita, cumpre apresentar ao leitor, mesmo que em linhas gerais, alguns pontos da perspectiva semiopragmática.

Breves notas metodológicas: da análise semiopragmática

Linguista de formação e inicialmente alinhado com uma prática de análise fílmica de caráter imanente que tem como principal filiação o trabalho de Christian Metz, Roger Odin tem se dedicado à elaboração e defesa de um modelo que possa aliar a abordagem imanentista a uma perspectiva pragmática no exercício da análise audiovisual. De acordo com esse modelo, que o autor denominou como "semiopragmática", seria preciso interrogar não apenas os modos pelos quais os textos audiovisuais são construídos, mas considerar, simultaneamente, as maneiras pelas quais essa construção pode afetar e conduzir a experiência dos espectadores em contextos de recepção distintos.

Contudo, essa postura teórico-metodológica, que deseja relacionar o "espaço da realização" ao "espaço da leitura" no momento da análise (Odin, 2000), não teria como pretensão compreender aquilo que se passa individualmente com cada espectador frente a um determinado filme, de acordo com uma perspectiva mais propriamente cognitivista. Pelo contrário, partindo de uma postura heurística, que constrói teoricamente esses espaços e permite ao analista formular questões que nortearão a análise, a semiopragmática aposta na capacidade de conseguir delimitar um conjunto restrito de modos de produção de sentidos e afetos que possibilitem "apreender as diferenças que podem pontuar a maneira como os públicos/espectadores interagem com os textos fílmicos e audiovisuais (inclusive pictóricos e fotográficos) em diversas situações" (Bamba, 2013, p. 224).

Nesse sentido é que, para Odin, o leitor/espectador não seria simplesmente o receptor de uma mensagem cuja arquitetura deve ser destrinchada pelo analista, segundo uma abordagem exclusivamente estrutural, mas sim "um ponto de passagem de todo um feixe de determinações" (Odin, 2000, p. 11, tradução nossa) que seria preciso levar em conta no exercício da análise. 
Ainda que questões genéricas não estejam no centro das preocupações do autor, a distinção entre ficção e documentário tem lugar em sua argumentação, na medida em que configura posturas distintas por parte do espectador de acordo com a forma como cada um desses "modos" gundo Odin,

se a documentarização responde ao meu desejo de real, interpelando-me diretamente enquanto pessoa de carne e osso (sob o risco de que eu mobilize minhas defesas), a ficcionalização, por sua vez, me propõe uma mediação - por detrás do baluarte ficcional - para que eu possa acessar o real sem que eu me sinta diretamente colocado em questão: aí reside, indiscutivelmente, sua própria virtude. Se o desejo de ficção tem tal poder na sociedade, isso se dá, precisamente, porque ele me oferece um modo pacificado de relação com o real. Uma teoria do documentário não pode subestimar tal poder (Odin, 2000, p. 128, tradução nossa) ${ }^{5}$

O trecho citado revela, ainda, a premissa central da argumentação do autor no desenvolvimento da semiopragmática e que consiste na afirmação de que o processo de ficcionalização estaria no centro das experiências espectatoriais humanas, não apenas pelo fato do regime ficcional ocupar um espaço privilegiado em nosso espaço sociocultural, mas porque o "desejo de ficção" responderia a um "grande regime de funcionamento psíquico" (Odin, 2000). A partir dessa premissa, e da centralidade em que ela coloca o modo e a leitura ficcionalizantes, é que o autor irá arquitetar outros posicionamentos possíveis por parte do espectador, tais como as leituras documentarizantes, performativas, autobiográficas, etc., segundo um modelo em que seria teoricamente possível acrescentar, ainda, outras possibilidades.

No que diz respeito mais especificamente ao nosso objeto de análise, é importante compreender, sobretudo, a distinção que é feita por Odin entre documentário, modo documentarizante e leitura documentarizante. Segundo ele,

O modo documentarizante é constituído pelo conjunto de processos de produção de sentidos e afetos necessários à produção documentarizante (seja no espaço da produção como no da leitura). A leitura documentarizante pode ser acionada com relação a qualquer filme (aí incluídos filmes de ficção). Por fim, o documentário corresponde ao conjunto de produções que demandam serem lidas de acordo com o modo documentarizante (Odin, 2000 , p. 128 , tradução nossa $)^{6}$.

É possível depreender, a partir do trecho citado, alguns posicionamentos que serão úteis para a discussão aqui proposta e que deverão, de certa forma, orientar a análise que se segue: em primeiro lugar, a afirmação da existência de uma relação estreita e necessária entre as leituras que são acionadas pelo filme e os gêneros ou subgêneros a que estes se veem vinculados; em segundo lugar, a afirmação de que leituras que a princípio caracterizam modos distintos de produção podem coexistir ao longo de um mesmo filme.
Dito em outras palavras, segundo o posicionamento de Odin (e que aqui será adotado), o espectador tanto pode estabelecer uma leitura documentarizante no interior de um filme de ficção - podemos pensar, por exemplo, na recepção frente ao uso de imagens de arquivo no cinema ficcional, ou ainda na curiosa experiência do espectador frente a uma obra de ficção "baseada em fatos reais" - quanto, frente a um filme documentário, pode acionar uma leitura ficcionalizante - aqui, por outro lado, podemos pensar seja na recepção de experiências documentais consideradas "de fronteira", seja em uma possível fragilidade do regime de crença que é estabelecido entre o espectador e a obra. Seguindo essa linha de raciocínio, conclui-se que o mesmo pode ocorrer com relação a outros regimes de leitura possíveis e que, ao analista, cabe a tarefa central de identificar a maneira como diferentes posicionamentos do leitor/espectador são convocados em uma determinada obra audiovisual.

Feitas essas considerações preliminares sobre a semiopragmática, é possível orientar nossa análise sobre o objeto específico que aqui nos interessa a partir de algumas questões iniciais que essa perspectiva nos permite colocar: quais leituras, a princípio, podem caracterizar aquilo que comumente se denomina como documentário musical?; quais estratégias audiovisuais caracterizam, por outro lado, um regime de leitura biográfico e que lugar, no interior dessas estratégias, a música ocupa ou pode ocupar?; que leituras a utilização da música e, mais especificamente a canção, podem acionar na biografia documental?. Essas, dentre outras questões que possam a partir delas se desdobrar durante a análise se $A$ música segundo Tom Jobim, tentarão ser enfrentadas ao longo desse texto. 


\section{Das leituras acionadas em A música segundo Tom Jobim}

Ao som de uma versão instrumental de Garota de Ipanema, espaço e tempo começam a ser delimitados para o espectador nas imagens sobre as quais se sobrepõem os créditos do documentário A música segundo Tom Jobim. Nesses primeiros minutos, se seguem diferentes imagens em movimento em preto e branco que, por meio da montagem, simulam um movimento de aproximação à cidade do Rio de Janeiro, provavelmente em meados dos anos de 1940: um avião da companhia Panair do Brasil sobrevoa uma faixa litorânea circunscrita por morros; da vista aérea da praia, o olhar se aproxima e observa carros que circulam por vias ao longo das quais se percebe uma cidade em processo de urbanização; o espectador é levado, logo em seguida, ao nível das ruas, acompanhando uma "câmera-veículo" que circula, ao ritmo do andamento musical, entre os automóveis que se dirigem para atravessar um túnel. A aproximação finalmente se conclui com uma "câmera-pedestre", que circula entre os banhistas de uma praia carioca e os observa. No nível sonoro crescem, ao final dessa sequência de abertura, sons de aplausos que antecipam o espaço em que transcorre um show.

Desse Rio de Janeiro dos anos de 1940, passamos, a seguir, à imagem em cores de uma plateia que vibra quando a cantora Gal Costa, aparentemente décadas mais tarde ${ }^{7}$, começa a interpretar $\mathrm{Se}$ todos fossem iguais a você, composição de Tom Jobim em parceria com Vinícius de Moraes. Ao final dessa performance, o personagem-título do documentário finalmente adentra ao palco/tela, onde é abraçado pela cantora e ovacionado pelo público.
O breve trecho descrito condensa, em certa medi$\mathrm{da}$, o intervalo de tempo durante o qual transcorreu a carreira do artista. Paralelamente, inaugura uma liberdade temporal que será característica da montagem nesse documentário. Em A música segundo Tom Jobim, a cronologia tecida pelos sons e imagens não é necessariamente linear

Também nesse documentário não há trechos de entrevistas com amigos ou familiares do compositor, cujas palavras poderiam informar detalhes da intimidade do artista para além do palco. O palco, em diferentes materializações, é, na verdade, o espaço principal em que transcorre a maior parte desse filme de aproximadamente uma hora e vinte minutos de duração, exclusivamente tecido a partir de fotografias e filmagens de arquivo que foram garimpadas durante o processo de produção e articuladas, na montagem, com diferentes performances das composições musicais de Tom Jobim.

Se a palavra falada, matéria mais comum das cinebiografias documentais, aqui é escassa, percebe-se, por outro lado, que as palavras que são cantadas e muitas vezes repetidas nos diferentes palcos que são apresentados no filme podem, muitas vezes, produzir efeitos para além da esfera do deleite musical. Nesse sentido é que é possível perceber, por exemplo, que a canção interpretada no momento em que a imagem de Tom Jobim surge pela primeira vez no documentário não está ali por acaso - as palavras entoadas por Gal Costa podem ser lidas pelo espectador não apenas como parte de uma obra autoral, mas como se referindo ao próprio compositor, com o intuito de evidenciar o caráter ímpar de sua obra: "Se todos fossem iguais a você/ que maravilha viver/ Uma canção pelo ar/ uma mulher a cantar/ Uma cidade a cantar....".
Ao final desse trecho, vemos Tom Jobim dedilhar algumas notas no piano. A imagem subitamente congela, prenunciando um novo salto no espaço e no tempo que é antecipado, no plano sonoro, por uma canção que se inicia, agora na voz de Elizete Cardoso. Começa, a partir daí, uma sequência de aproximadamente dois minutos durante a qual essa canção se desenrolará em sua integralidade. As fotografias em preto e branco que são articuladas nesse intervalo, interrompidas vez ou outra por trechos da performance de Elizete, apresentam algumas informações sobre os primeiros passos do artista, assim como alguns dados pessoais de seu passado.

Vemos: fotos do músico ainda jovem, tanto ao piano quanto com um violão, o que demonstra seu caráter multi-instrumentista; um retrato de Tom ao lado de uma moça que logo mais deduziremos ter se tornado sua esposa (uma fotografia do casamento é apresentada na tela, além de outra onde o casal aparece ao lado de duas crianças); sua carteira de estudante da Faculdade de Arquitetura, datada de 1946, a qual se seguirá a da afiliação à associação dos compositores profissionais do Rio de Janeiro em 1952.

Mais uma vez é possível perceber que a palavra cantada pode contribuir na biografia do artista que o espectador aos poucos tenta reconstituir a partir da matéria audiovisual. Articulada com diferentes imagens em que se vê Tom Jobim ao lado de Vinícius de Moraes, ouve-se Elizete entoar a importância dessa longa parceria: "Não há você sem mim/e eu não existo sem você". As imagens remetem, ainda, à montagem teatral de Orfeu da Conceição, obra de Tom e Vinícius, assim como ao filme Orfeu negro, baseado nesta e dirigido por Marcel Camus em 1959. Nesse trabalho me- 
ticuloso da montagem, a voz que canta pode, assim, cumprir uma dupla função: ao mesmo tempo em que apresenta ao espectador uma obra musical, ela pode acrescentar significados novos à trajetória do artista que é tecida na tela.

É importante afirmar, nesse sentido, que ainda que as imagens descritas nesse trecho sejam pouco eloquentes e, em certa medida, dependentes do grau de conhecimento prévio que o espectador possua sobre a vida e a obra de Tom Jobim, elas possibilitam um grau mínimo de articulação narrativa segundo o que se espera de uma chave de leitura biográfica. Não somos informados, por exemplo, de "detalhes" que nosso hábito como consumidores de cinebiografias pode nos fazer desejar, tais como o nome da esposa dos filhos, ou mesmo dos parceiros que surgem ao lado de Tom nas diferentes fotos. Do mesmo modo, ficamos sem conhecer o percurso que o levou da Faculdade de Arquitetura para a carreira musical. Se aqui há a possibilidade de uma biografia, observa-se que ela de fato não se alinha àquilo que é mais comum no cenário do espaço documental biográfico contemporâneo e que, exatamente por isso, pode tanto frustrar as expectativas de muitos dos espectadores do filme, quanto ser louvada por sua originalidade.

Observa-se, ainda, que a narrativa pouco convencional de A música segundo Tom Jobim, além de abrir mão da palavra falada, opta por se centrar, quase que exclusivamente, nos aspectos da trajetória profissional do personagem-título, recusando-se com isso a atender um desejo voyeurista que de certo modo caracteriza as práticas de leitura biográficas. Mesmo assim, é possível identificar, especialmente a partir de alguns momentos do filme, o preenchimento daquele que seria um pré-requisito básico do gênero:
A multiplicidade das formas que integram o espaço biográfico oferece um traço comum: elas contam, de diferentes modos, uma história ou experiência de vida. Inscrevem-se assim, para além do gênero em questão, numa das grandes divisões do discurso, a narrativa, e estão sujeitas, portanto, a certos procedimentos compositivos, entre eles, $\mathrm{e}$ prioritariamente, os que remetem ao eixo da temporalidade (Arfuch, 2010, p. 111).

Contudo, como já observamos anteriormente, a temporalidade não é arquitetada de forma linear nesse filme, o que torna sua linha narrativa (e, portanto, biográfica) fragmentada - e, consequentemente, requer do espectador uma postura ativa para que ele possa segui-la ou mesmo reconstituí-la a partir das imagens e sons que se seguem na tela.

Dos primeiros minutos de filme aqui descritos em diante, as marcas temporais, assim como a referência a determinados acontecimentos da trajetória do compositor, se encontrarão dispersas ao longo de uma série de performances musicais nas quais figuras notáveis (e outras menos conhecidas) da cena musical nacional e internacional dão voz às composições de Tom Jobim.

Nesse contexto, será possível identificar um outro uso da palavra no filme. Além dos significados que muitas vezes são veiculados pela palavra cantada, palavras escritas em cartazes, materiais de divulgação e capas de disco que por vezes surgem na tela acrescentam novas informações a respeito da trajetória do artista. Um exemplo evidente está naquelas que foram escritas por Tom para a contracapa de Chega de Saudade, LP de João Gilberto que foi marco inaugural da Bossa Nova.
Também é por meio das palavras registradas em mais um documento de identificação profissional do compositor que ficamos sabendo, por exemplo, a respeito de sua instalação nos EUA nos anos de 1960.

Ao mesmo tempo, de um ponto de vista semiopragmático, se observa que a profusão de interpretações das composições de Tom Jobim que caracteriza a maior parte do documentário conduz à percepção, pelo espectador, daquele que parece ser o argumento central do filme: a afirmação da larga influência da obra do compositor dentro e fora do Brasil. Nesse sentido, se evidencia que A música segundo Tom Jobim pode ser apreciado segundo outras chaves de leitura que não a biográfica e que estas, inclusive, podem ser acionadas paralelamente pelo espectador ao longo do documentário, incluindo aquela que permite caracterizar esse filme como um discurso de homenagem e monumentalização da obra do compositor.

Ainda no que diz respeito às performances musicais, é possível afirmar, ainda, que o prazer que delas pode depreender o espectador, em certa medida irá se relacionar ao grau de conhecimento que este possui sobre o cenário musical de maneira mais ampla. A opção dos diretores em identificar os intérpretes das composições unicamente nos créditos finais é o que permite configurar esses efeitos distintos, conformando desde a leitura daquele que desconhece nomes como Oscar Peterson, Sammy Davis Jr., Agostinho dos Santos, Dizzy Gillespie, Judy Garland, etc., mas que pode apreciar sensorialmente suas interpretações e o desenrolar de múltiplas interpretações presentes no documentário segundo uma leitura cujo foco e deleite está na apreciação do valor artístico dessas performances (de acordo com o que Odin caracteriza como uma 
"leitura estetizante"), até aquele que faz da descoberta da identidade desses diferentes intérpretes uma fonte de entretenimento.

Somente próximo ao final do documentário é que novos dados da vida privada do artista serão mais uma vez apresentados, com a introdução de fotos onde ele, agora mais velho, aparece ao lado de Ana Jobim e dos filhos que teve com ela. Um certo tom nostálgico começa a ser introduzido aos poucos nesses minutos finais, especialmente a partir da interpretação de Anos dourados por Tom e Chico Buarque, durante a qual surge a imagem de uma partitura em que estão registradas palavras por meio das quais o compositor expressa as saudades que sente de Vinícius, em um movimento que de certa forma remete o espectador de volta ao início do documentário. Nesse momento, mais uma vez, a palavra cantada acrescenta significados, ao sugerir que a parceria Tom e Vinícius configurou os "anos dourados" da carreira do artista.

Ainda como parte desse movimento circular de retorno, surge, em seguida, a imagem noturna da silhueta feminina dos morros cariocas enquanto, no palco, alguns dos maiores nomes da MPB interpretam Lamento no morro na praia de Copacabana:"Não posso esquecer o teu olhar longe dos olhos meus/ $\mathrm{Ai}$, o meu viver é te esperar pra te dizer adeus". Ao som dessas palavras, surgem fotografias de Tom com uma criança em um cenário com neve. Para os que conhecem a trajetória do artista, essas imagens, em conjunção com a letra da canção, remetem ao retorno de Tom Jobim para os EUA no final da vida, que é igualmente sugerida pelas imagens seguintes, nas quais acompanhamos o músico durante a interpretação de Girl from Ipanema no Carnegie Hall. Ao final dessa apresentação, os aplausos da plateia ecoam e vão se multiplicar em imagens de outras plateias que ocuparam tempos e espaços distintos na trajetória musical de Tom Jobim.

Os minutos finais do documentário remetem, assim, a outra postura espectatorial possível frente ao documentário, que é a de sua fruição como uma espécie de grande concerto musical. $\mathrm{O}$ som dos aplausos vai aos poucos sendo substituído por uma composição instrumental melancólica, ao mesmo tempo em que as últimas imagens revelam a homenagem que foi feita ao compositor pela Estação Primeira de Mangueira, pouco tempo antes de sua morte. A estratégia principal de composição do filme se revelará, enfim, nas palavras de Tom que os diretores se dispuseram a seguir e que surgirá escrita na tela sobre um fundo negro, antecedendo os créditos de encerramento do documentário: "A linguagem musical basta".

\section{Considerações finais}

Da tentativa de orquestrar uma cinebiografia tendo como matéria principal as composições musicais do artista, A música segundo Tom Jobim se configura como um filme que aponta para a possibilidade de expansão dos limites do documentário biográfico musical para além de sua fórmula mais corrente, normalmente centrada no recurso dos depoimentos que são registrados via entrevistas. A observação, durante essa breve análise, das diferentes maneiras pelas quais os diretores, Nelson Pereira dos Santos e Dora Jobim, conseguiram explorar as articulações da matéria musical com as diferentes imagens de arquivo tentou evidenciar, ain$\mathrm{da}$, a particularidade como a voz e a palavra, recursos mais comuns desse tipo de produção, foram utilizadas no documentário.
Ao mesmo tempo, observamos que a opção por este privilégio da matéria musical se vê aliada, no filme, a uma liberdade temporal na construção de uma possível cronologia da vida do artista, cuja "leitura biográfica" requer uma postura ativa do ponto de vista da recepção. De modo semelhante, a recusa dos diretores em referenciar a maior parte das imagens do filme contribui para a configuração de uma narrativa que se abre a diferentes experiências de fruição. Percebemos, nesse sentido, que é sobretudo por meio do diálogo entre a materialidade audiovisual com o conhecimento prévio de cada espectador que dados da biografia de Tom Jobim podem ser delimitados com contornos mais ou menos precisos pelos espectadores. Essa dependência, por sua vez, se relaciona à possibilidade do acionamento paralelo de leituras distintas ao longo desse filme no qual o biográfico e o musical se articulam e se tencionam ao ritmo do espectador.

\section{Referências}

ALTMAN, Rick. Film genre. London: British Film Institute, 1999

ARFUCH, Leonor. O espaço biográfico: dilemas da subjetividade contemporânea, Rio de Janeiro: UERJ, 2010.

BAMBA, Mahomed. Os espaços de recepção transnacional dos filmes: propostas para uma abordagem semiopragmática. In: Crítica cultural, v. 8, n. 2, jul./dez. 2013, p. 219-237.

CARVALHO, Márcia. O rock desligado de Lóki. In: Doc On-line, n. 12, ago. 2012, p. 75-99. 
A biografia cantada de $A$ música segundo Tom Jobim In: Ouvir o documentário: vozes, música, ruídos, Salvador: Edufba, 2015, p. 121-132.

LIMA, Cristiane. Música em cena: à escuta do documentário musical brasileiro. 2015. Tese (Doutorado em Comunicação) - Programa de Pós-Graduação em Ciências da Comunicação, UFMG, Belo Horizonte, 2015.

MAIA, Guilherme. Aspectos da música no documentário brasileiro contemporâneo: algumas reflexões sobre o fazer e o pensar. In: Doc On-line, n. 12, ago. 2012, p. 100-126.

ODIN, Roger. De la fiction. Bruxelas: De Boeck, 2000

Cinéma et production du sense, Paris: Armand Colin, 1997.

Les espaces de communication: introduction à lá sémiopragmatique. Grenoble: PUG, 2011.

RAMOS, Luciano. Como explicar o ímpeto do documentário musical brasileiro? In: Doc On-line, n. 12, ago. 2012, p. 127-150.

TAVARES, Denise. Subjetividades transbordantes: apontamentos sobre o documentário biográfico, memória e história. In: Doc On-line, n. 15, dez. 2013, p. 111-131.

\section{Referências Audiovisuais}

ALVES, Oscar Rodrigues. MELLO, Branco. [Filme]. Titãs: a vida até parece uma festa. Produção de Oscar Rodrigues Alves. Direção de Oscar Rodrigues Alves e Branco
Mello. Brasil, Academia de Filmes, Casa Cinco, 2008. 100 min. Cor. Son.

CAMUS, Marcel. GORDINE, Sacha. [35 mm]. Orfeu

Negro. Produção de Sacha Gordine. Direção de Marcel Camus. Brasil/França, Dispat Films, Gemma, Tupan Filmes, 1959. 100 min. Cor. Son.

FARIA JR., Miguel. [Filme]. Chico: artista brasileiro. Produção e direção de Miguel Faria Jr. Brasil, 1001 Filmes, Globo Filmes, 2015. 110 min. cor. Son.

FONTOURA, Antonio Carlos da. FONTOURA, Letícia. [Filme HD]. Somos tão jovens. Produção de Antonio Carlos da Fontoura e Letícia Fontoura. Direção de Antonio Carlos da Fontoura. Brasil, Canto Claro Produções Artísticas, 2013. 104m. Color. Son.

JAGUARIBE, Izabel. BRUNO, Beto. [35 mm]. Paulinho da Viola - meu tempo é hoje. Produção de Beto Bruno. Direção de Izabel Jaguaribe. Brasil, Video Filmes, 2004. 83 min. Cor. Son.

MATOS JR., Décio. [Filme 35 mm]. Fabricando Tom Zé. Produção de Omar Jundi. Direção de Décio Matos Jr. Brasil, Goiabada Productions, Muiraquitã Filmes, Primo Filmes, 2004. 85 min. cor. Son.

MOREIRA SALLES, João. BRUNO, Beto. [35 mm]. Nelson Freire. Produção de Beto Bruno. Direção de João Moreira Salles. Brasil, Video Filmes, 2003. 102 min. Cor Son.

PEREIRA DOS SANTOS, Nelson; JOBIM, Dora. [Filme
HDCam]. A música segundo Tom Jobim. Produção de Marcia Pereira dos Santos, Maurício Andrade Ramos e Rodrigo Saturnino. Direção de Nelson Pereira dos Santos e Dora Jobim. Brasil, Natura, Regina Filmes, Instituto Antonio Carlos Jobim, 2011. 88m. color. Son.

ROCHA, Eryk. [Filme HD]. Jards. Produção e direção de Eryck Rocha. Brasil, Aruac Filmes, Biscoito Fino, Canal Brasil, 2012. 93 min. cor. Son.

SILVEIRA, Breno. BUARQUE DE HOLLANDA, Pedro. [Filme 35 mm]. 2 Filhos De Francisco: A história de Zezé Di Camargo \& Luciano. Produção de Pedro Buarque de Hollanda et al. Direção de Breno Silveira. Brasil, Columbia TriStar Filmes do Brasil, Globo Filmes, Conspiração Filmes, 2005. 127 min. cor. Son.

SANTA CRUZ, Cibele. [Filme 35 mm]. Gonzaga: de pai para filho. Produção de Cibele Santa Cruz. Direção de Breno Silveira. Brasil, Conspiração Filmes, Downtown Filmes, D Produções, 2012. 120 min. cor. Son.

WERNECK, Sandra; CARVALHO, Walter. FILHO, Daniel. [Filme 35 mm]. Cazuza: o tempo não pára. Produção de Daniel Filho. Direção de Sandra Werneck e Walter Carvalho. Brasil, Cineluz, Globo Filmes, Lereby Productions, 2004. $90 \mathrm{~min}$. cor. son.

Notas

1 Este artigo foi desenvolvido como ação dos projetos de pesquisa "O Cinema Musical na América Latina: ficção, documentários e novos formatos", apoiado pelo edital FAPESB 11/2013 de Apoio à Formação e Articu- 
lação de Redes de Pesquisa no Estado da Bahia, e "Os musicais no Brasil: cinema e televisão", apoiado pelo edital Universal MCTI/CNPq No 14/2013.

2 Doutora em Comunicação e Cultura Contemporâneas (UFBa). Professora permanente do Programa de pós-graduação em Comunicação e Cultura Contemporâneas da Universidade Federal da Bahia (PósCom/UFBa - Av. Barão de Geremoabo, s/no, Campus de Ondina, CEP 40.170-115, Salvador - Bahia). E-mail: sandrixcoeIho@gmail.com.

30 desenvolvimento, por Odin, da perspectiva semiopragmática pode ser acompanhado em suas obras $\mathrm{Ci}$ nema et production de sens (Armand Colin, 1990), De la Fiction (De Boeck, 2000) e Les Espaces de Communication: introduction à la sémiopragmatique (PUG, 2012).

4 Vale dizer que, em sua argumentação, Odin utiliza conceitos como "produção", "modo" e "leitura" para dar conta dos aspectos envolvidos na recepção dos gêneros.

5 No original: "Si la documentarisation répond à mon désir de réel em m'interpellant directment em tant que personne réelle, au risque de me voir mobiliser mes défenses, la ficcionalisation, elle, me propose une médiation pour accéder au réel sans que je me sente directment mis em cause: derrière le rempart du fictif; c'est là indiscutiblement sa vertu propre. Si le désir de fiction à um tel poids dans la sociéte, c'est précisément parce qu'il m'offre um mode de relation pacifié au réel. Une théorie du documentaire ne saurait sous-estimer ce poids" (Odin, 2000, p. 128).

6 No original: "Le mode documentarisant est constitué par l'ensemble des processus de production de sens et d'affects nécessaires à la production documentarisante (dans l'espace de la réalisation ou de la lecture). La lecture documentarisante peut être mise en ouvre sur tout film (y compris les films de fiction). Enfin, le documentaire correspond à l'ensemble des productions qui demandent à être lues sur le mode documentarisant" (Odin, 2000, p. 128).

7 Apenas a partir dos créditos finais é possível localizar as imagens desse show com sendo de Tributo a Tom Jobim, realizado em 1993, portanto um ano antes da morte do compositor, e registrado por Walter Salles Jr. 